\title{
Friedreich's Ataxia With Nephrotic Syndrome and Convulsive Disorder: Clinical and Neurophysiological Studies With Renal and Nerve Biopsies and An Autopsy
}

\author{
G.V. WATTERS. S.H. ZLOTKIN, B.S. KAPLAN, P. HUMPHREYS, and K.N. DRUMMOND
}

SUMMARY: In a sibship of four, Friedreich's ataxia and minimallesion nephrotic syndrome occurred in two siblings, a third sibling had Friedreich's ataxia, but no evidence of nephrotic syndrome; the fourth sibling had neither condition. The chance of Friedreich's ataxia and minimal lesion nephrotic syndrome occurring in two siblings is small, and suggested a common immunological abnormality. High dose prednisone and antimetabolites given for the nephrotic syndrome did not appear to affect the course of Friedreich's ataxia.

The two siblings with Friedreich's ataxia and nephrotic syndrome developed epilepsy at age 15 vears. All three children with Friedreich's ataxia had abnormal

RÉSUMÉ: Dans une fratrie de 4 enfants l'ataxie de Friedreich se retrouva associée à un syndrome nephrotique à lésion minime chez deux sujets alors qu'un autre membre de la famille ne présentait que l'ataxie de Friedreich et que le dernier était sain. Cette association rare suggère un mécanisme immunologique commun. De fortes doses de prednisone et d'antimetabolites données pour traiter le syndrome néphrotique ne semblent pas avoir touché l'évolution de l'ataxie.

Les deux enfants présentant l'association des 2 maladies développèrent une épilepsie à 15 ans. Les 3 ataxiques de cette electroencephalograms (EEGs). These epileptiform EEG abnormalities were probably inherited from the mother, who had spike wave epilepsy. The neurologic deficits of Friedreich's ataxia, in turn, may have allowed the EEG trait to be expressed as a seizure disorder. The progressive ataxia and epileptic, sometimes myoclonic, seizures in these patients and the dentate nucleus changes in the autopsied patient were consistent with the diagnosis of dyssynergia cerebellaris myoclonica. This suggested that the latter disorder may represent a coincidence of th'o genetic entities: Friedreich's ataxia and spike wave epilepsy.

famille avaient un EEG anormal, probablement hérité de la mère qui a une épilepsie pointe-onde. Nous postulons que l'ataxie de Friedreich a permis à ce trait électroencéphalographique d'être exprimé comme un désordre convulsif. L'ataxie et l'épilepsie progressives de ces patients, ainsi que les modifications au noyau dentlé à l'autopsie sont compatibles avec le diagnostic de dyssynergia cerebellaris myoclonica (Ramsay Hunt). Ceci suggère que cette dernière maladie est peut-être la coïncidence de deux entités génétiques: l'ataxie de Friedreich et l'épilepsie pointeonde.
From the Neurology and Nephrology Services of The Montreal Children's Hospital and McGill University, Montreal.

Reprint requests to Dr. Gordon V. Watters, Neurology Service. The Montreal Children's Hospital, 2300 Tupper Street. Montreal. Quebec, Canada. H3H IP3.

Presented at the Canadian Congress of Neurological Sciences, June 1979, Halifax, Nova Scotia.

\section{INTRODUCTION}

Friedreich's ataxia is the most common of the hereditary ataxias or spinocerebellar ataxias. In the Quebec cooperative study of Freidreich's ataxia (Andermann et al. 1976), the associated abnormalities in the series of 58 patients included cardiomyopathy $(51.7 \%)$, diabetes mellitus (19\%), optic atrophy $(5.2 \%)$, and nerve deafness $(5.2 \%)$. This report describes the occurrence of minimal lesion nephrotic syndrome (MLNS) in two of three siblings who had Friedreich's ataxia, the electroencephalographic and/or seizure disorder which occurred in all three, their electromyographic and nerve and muscle biopsy studies, and the autopsy of one case.

\section{PEDIGREE OF DISORDERS}

There were four children in this family (figure 1). The first born child, a boy, is alive and well. The other three children (patients 1,2, and 3) all developed Friedreich's ataxia. Of these three, the two youngest also developed minimal lesion nephrotic syndrome and convulsive disorder. All three had abnormal electroencephalograms, abnormal electrocardiograms and evidence of cardiomyopathy.

The parents of these four children were not consanguinous. The mother, her brother's daughter and the mother's paternal uncle had epilepsy.

\section{NEUROLOGICAL FINDINGS}

Patient 1 a girl, at 6 years had bilateral horizontal nystagmus, kyphoscoliosis, pes cavus deformities, decreased to absent stretch reflexes, ataxic gait, and bilateral Babinski responses. Confined to a wheelchair by age 9 she developed a severe scoliosis. Now, at age 26 she is severely 


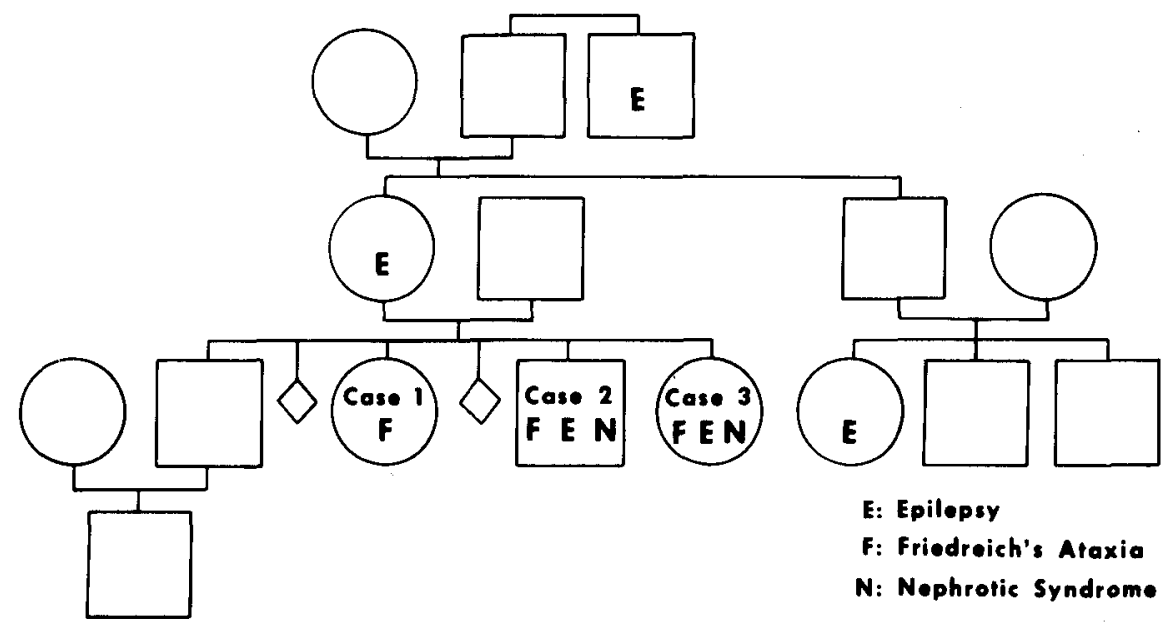

Figure I - Pedigree of family with Friedreich's ataxia, minimal lesion nephrotic syndrome, and epilepsy

handicapped neurologically, but has never shown evidence of nephrotic syndrome, nor has she had a seizure.

Patient 2 , a boy, presented at age $51 / 2$ with the gradual onset of generalized edema due to nephrotic syndrome and was treated with combinations of prednisone, nitrogen mustard, and cyclophosphamide. Over the next two years he became ataxic, developed bilateral pes cavus, areflexia, horizontal nystagmus and bilateral $\mathrm{Ba}$ binskis. By age 9 he was confined to a wheelchair. He developed scoliosis, spasticity of his lower limbs, scanning speech and finally a generalized seizure disorder at age 15 years. At age 17 he had a renal vein thrombosis and died at age 20 . The post-mortem findings are described below.

Patient 3 a girl, had three febrile convulsions between ages 3 and 4 . She was noted at age $5 \frac{1}{2}$ to have mild ataxia, bilateral pes cavus, reduced knee and ankle stretch reflexes and bilateral Babinskis. At age 11 she was confined to a wheelchair. At age 13 she developed pedal edema with nephrotic syndrome. At age 15 she had a major seizure, and perhaps several others. A few months later she developed multifocal myoclonic jerking on two occasions. At age 17 she had scanning speech, gross ataxia of the upper limbs, absent stretch reflexes, absent position sense in the lower limbs, and severe pes cavus. Now, at age 20 she is severely incapacitated with end stage Friedreich's ataxia.

\section{NEPHROTIC SYNDROME DATA}

As noted, patients 2 and 3 developed minimal lesion nephrotic syndrome. Patient 2 presented at $51 / 2$ years after 3 days of anorexia, irritability, progressive generalized edema of the face, scrotum and legs, and ascites. Blood pressure was normal.

In the urine there were granular and hyaline casts, albumin was 4 plus, and 24-hour protein excretion was 3.1 grams. Hemogram was normal, but serum sodium was 130 , chloride 100 , and potassium $5.0 \mathrm{mEq} / 1$. BUN was $22 \mathrm{mgm} / \mathrm{dl}$, serum cholesterol 442 $\mathrm{mgm} / \mathrm{dl}$, and serum total protein 5.7 and albumin $2.3 \mathrm{~g} / \mathrm{dl}$.

He was treated with meticorten, adreno-corticotrophic-hormone (ACTH), and diuretics which induced a remission. A year later nitrogen mustard was given because he had been steroiddependent for a year, and had began to relapse on $60 \mathrm{mgm}$ of prednisone per day. Intravenous nitrogen mustard was given $0.1 \mathrm{mgm} / \mathrm{kg}$ daily for four days, which induced a temporary remission. Over the next 10 years he had many relapses managed successfully with prednisone.

In 1973 at age 17 he was given a course of cyclophosphamide $50 \mathrm{mgm} /$ day for six months and then predni. sone $60 \mathrm{mgm} / \mathrm{day}$ for one month, followed by $60 \mathrm{mgm}$ every second day for 6 months.

A year later he had pain in the right flank, red blood cells in his urine, and an intravenous urogram demonstrated a normal left kidney, but no right kidney. A diagnosis of renal vein thrombosis secondary to nephrotic syndrome was made. With hydration and analgesia he recovered.

In summary, he had steroidresponsive, but steroid-dependent minimal lesion nephrotic syndrome, onset age 5 , complicated by renal vein thrombosis. Vigorous therapy with corticosteroids and other immunosuppressants did not appear to alter the course of his underlying neurologic disease. He died at age 20 years (see autopsy below).

Patient 3 at age 12 developed leg edema. Her blood pressure was $120 / 75$ $\mathrm{mmHg}$; she had no signs of congestive heart failure, and the 24-hour urine protein excretion was $9 \mathrm{mgm}$ in a volume of $300 \mathrm{ml}$. Urinalysis, hemogram, BUN, serum creatinine, serum albumin, and complement were all normal. The edema resolved spontaneously.

One year later she presented with pedal edema of one week's duration, her blood pressure was $115 / 60 \mathrm{~mm} \mathrm{Hg}$, and there were no abnormal findings other than those of Friedreich's ataxia. On this occasion the urine sediment was normal. Two 24-hour collections of urine contained 2.9 and 2.8 grams of protein respectively. Hemogram and serum electrolyte concentrations were normal. BUN was 15 , serum creatinine was 0.7 , and cholesterol $365 \mathrm{mg} / \mathrm{dl}$. The serum total protein was 5.0 and albumin $1.99 \mathrm{~g} / \mathrm{dl}$. Rheumatoid factor, $\mathrm{ANF}$, and ANA were negative; the serum $C_{3}$ was normal at 125 and the $C_{4}$ was slightly reduced at $19 \mathrm{mgm} / \mathrm{dl}$. The serum immunoglobulin concentrations were IgG 220, IgM 140, and IgD $3.7 \mathrm{mgm} / \mathrm{dl}$. An intravenous urogram was normal. PPD was negative and she was treated for one month with prednisone 20 mgm t.i.d. and a $17 \mathrm{mEq}$ sodium diet. Proteinuria lasted one week.

She remained in remission for a year and then had three recurrences which responded to prednisone within a week. She was not treated with cyclophosphamide. BUN and creatinine concentrations remained normal three years after the onset of the nephrotic syndrome.

The total prednisone given was 60 
$\mathrm{mgm} / \mathrm{day}$ for four one-month periods and $60 \mathrm{mgm}$ every second morning for two six-month periods. She is alive at age 20 but has severe neurological deficits.

\section{KIDNEY BIOPSY IN PATIENT 3}

At age 12, one month after the onset of the nephrotic syndrome, a percutaneous kidney biopsy was done. Five glomeruli were examined by light microscopy, one was hyalinized while the others had a moderate increase in mesangial cells, a mild increase in mesangial matrix, and prominent endothelial cell nuclei. There was segmental thickening of the glomerular capillary walls and moderate thickening of Bowman's capsule, but no deposits.

By immunoflurescent microscopy, deposits of moderate intensity for $\mathrm{C}_{4}$ and $\mathrm{C}_{3}$ were present along glomerular capillary walls of 4 and 2 glomeruli respectively. Trace fluorescence for IgM was seen in one glomerulus.

No deposits were seen ultrastructurally but parts of the glomerular basement membrane were irregularly thickened and in some areas folded containing intramembranous cellular elements and debris. Within the mesangium there was deposition of basement membrane-like material. The endothelial and epithelial cells were swollen, and the foot processes of the podocytes were fused.

\section{IMMUNOLOGICAL STUDIES}

Studies were done to detect an immunological defect which might account for the occurrence of Friedreich's ataxia and MLNS in this family. The studies and the results are shown in table 1. The only abnormalities found were low serum IgG concentrations in the nephrotic patients, and on one determination in patient 3 , a decrease of circulating T-lymphocytes.

\section{AUTOPSY FINDINGS IN \\ PATIENT 2 AT AGE 20}

\section{Central Nervous System}

Post-mortem examination of the brain $(1300 \mathrm{gm})$ revealed a large, reddish-gray, recent infarct in the left superior frontal and cingulate gyri. This infarct was estimated to have occurred 2 - 3 days before death. There were also several separate, small, recent infarcts in the left midfrontal and inferior frontal gyri. The spinal cord was diffusely atrophied especially in the thoraco-lumbar segments.

\section{Heart}

The heart weighed 344 grams with pronounced left ventricular preponderance, a small, friable mural thrombus was found in the left ventricle. Recent thrombi partially occluded the abdominal aorta and iliac bifurcation. The left iliac artery was partially occluded by an organized thrombus.

\section{Kidneys}

The right kidney was pale and weighed 95 grams; the left kidney was congested and weighed 140 grams. Old, shallow, star-shaped scars were seen on the cortical surface of the upper pole of the right kidney and, on cut section, there was marked loss of parenchyma in the regions of these scars. The right kidney was swollen, congested, and flabby. There were no recent or old infarcts.

\section{HISTOLOGIC FINDINGS}

\section{Central Nervous System}

Microscopic examination of sections through the left and right cingulate gyri revealed areas of recent infarction, hemorrhage, and congestion. Myelin stains showed marked demyelination in the gracile and cuneate fasciculi, lateral corticospinal, anterior corticospinal, and posterior spinocerebellar tracts. Extensive gliosis was noted in the central regions of the fasciculi gracilis and cuneatus. The anterior horn cells were reduced in number, and there was complete loss of the dorsal root ganglia.

Examination of the cerebellum revealed focal degeneration and loss of Purkinje cells and a marked reduction in the number of cells in the dentate nucleus.

\section{Kidneys}

Histological examination of the right kidney confirmed the finding of remote infarcts in the cortex as well as in the medulla. In both kidneys there was passive congestion, acute tubular necrosis, focal interstitial nephritis, and occasional thrombi in the small vessels. The glomeruli appeared normal.

\section{Heart}

Although the sizes of the myocardial fibers varied, most were large and had focal myofibrillar degeneration. There was no evidence of an inflammatory reaction. The myocardial muscle cell nuclei were large and hyperchromatic. Many nuclei had a "box-car" appearances, others were spherical, and some were folded and irregular. In some, chromatin was clumped. Small, round,

TABLE I

Immunologic Studies In Three Children With Friedreich's Ataxia

\begin{tabular}{lcccc}
\hline & Patient 1 & Patient 2 & Patient 3 & Normal Range \\
\hline IgG & 840 & 420 & 200 & $770-1510 \mathrm{mg} / \mathrm{dl}$ \\
IgM & 260 & 185 & 130 & $36-224 \mathrm{mg} / \mathrm{dl}$ \\
IgA & 240 & 155 & 150 & $108-325 \mathrm{mg} / \mathrm{dl}$ \\
C3 & 125 & not done & 130 & $90-150 \mathrm{mg} / \mathrm{dl}$ \\
T-cell ('E' rosettes): & $51 \%$ & $51 \%$ & $31 \%$ & $50-70 \%$ \\
& & & $48 \%$ & \\
Delayed Skin Test: & not done & no response & Varidase +ve \\
Lymphocyte & & & & \\
Transformation & & & & \\
Response to: & & not done & normal \\
$\begin{array}{l}\text { Phythohemagluttinin } \\
\text { Poke weed mitogen }\end{array}$ & normal & normal & not done & normal \\
Concavolin A & normal & not done & normal \\
\hline
\end{tabular}


eosinophilic and basophilic, intranuclear, "inclusion-like" bodies, surrounded by a clear halo, were seen in many cells. Throughout the myocardium there was diffuse interstitial fibrosis. Transverse striations could be seen in most cells. Many degenerating cells contained lipochrome pigment, and occasional fibers had focal, myocytolytic degeneration.

Examination of the subendocardium revealed severe fibro-elastosis. No evidence of infarction could be found in the myocardium underlying a thrombus.

Involutional changes were seen in the thymus. There were many Hassall's corpuscles and some contained polymorphonuclear cells and lymphocytes in their central areas.

\section{EPILEPTIC SEIZURES AND ELECTROENCEPHALOGRAPHIC ABNORMALITIES}

Patient 1 had no epileptic seizures, but an EEG done at age 6 showed a diffuse dysrhythmia with an epileptic abnormality in the right temporal region. At age 14 she had a brief period of myoclonic spasms of her limbs. It was not clear whether these were flexor spasms of spinal cord origin, or myoclonic jerks.

Patient 2 had a generalized seizures disorder with onset at age 15 years. His EEG at age 6 and 7 was normal, but at age 9 showed a mild to moderate dysrhythmia posteriorly. His first seizure was generalized. An EEG 6 months later showed only minimal irregularities. Begun on anticonvulsants, compliance was poor and he had bouts of seizures about once a year. Repeat EEGs at age 16, 17, and 18 showed mild diffuse abnormalities. On no occasion was a spike wave discharge seen. He died at age 20 .

Patient 3 had three seizures with fever between ages 2 and 4 years. Her EEG at age 3 was minimally abnormal. She was treated with anticonvulsants. At age 7 after three years free of seizures medication was stopped. Her EEG showed a bi-occipital abnormality of mild degree.

She had no further seizures until age 14 , when she had myoclonic jerking of head, neck, trunk and extremities. Given clonazepam she had an episode of loss of awareness and Cheyne-
Stokes respiration. Clonazepam was stopped and the myoclonus disappeared having been present for a total of 36 hours. Her EEG showed a severe disturbance of cerebral activity with no lateralizing features. She was then free of seizure till age 15 when she had a prolonged major seizure and perhaps several other brief early morning seizures. Her EEG showed a typical spike wave discharge. She was begun on phenytoin and no further attacks occurred. However, two months later she developed myoclonic jerking involving the trunk and extremities which responded to clonazepam. Phenytoin and clonazepam were given and seizures ceased. After three months the parents discontinued the medication. There was no recurrence in the ensuing 9 months. Her EEG at age 16 when she had been off medication for 6 months, showed a local epileptiform abnormality in the right frontal and right mid-temporal region but no clinical accompaniment. At age 20, still off medication, she had no further seizures.

\section{ELECTROMYOGRAPHIC AND}

NERVE CONDUCTION STUDIES AND NER VE-MUSCLE BIOPSY

In patient 1 at age 8 a diagnosis of myopathy was made and confirmed, it seemed, by a muscle biopsy showing "myopathic features". At age 21 she had normal median nerve motor conduction velocity (MCV) of 50 meters/second ( $\mathrm{M} /$ sec.) and absence of the median nerve sensory potential. Electromyographic (EMG) findings were consistent with an upper motor neuron disorder; reduced motor unit potential (m.u.p.) recruitment for effort, but normal unit configuration.

Patient 2 at age 6 had normal EMG and nerve conduction studies. At age 14 years an incomplete study showed a slowed posterior tibial nerve MCV of 43.0 $\mathrm{M} / \mathrm{sec}$. with a normal distal latency.

At age $18 \mathrm{MCV}$ in the right median nerve was slightly slowed at 44.6 $\mathrm{M} / \mathrm{sec}$. Terminal motor latency and evoked potentials were normal. Sensory evoked potentials could not be obtained from the right median nerve and the right ulnar nerve using needle recording electrodes. EMG studies showed a marked reduction in recruitment of motor units with maximum effort, particularly in distal appendicular muscles. Motor unit configuration was, on the average, normal. These EMG findings were considered typical of an upper motor neuron disorder.

A biopsy of the gastrocnemius and sural nerve was done at age 18 . Most muscle fibers were normal in size with some atrophic fibers which were angular and grouped. There were increased central nuclei. Most fibers were histochemical Type II.

Epon sections of the sural nerve showed severe loss of myelinated fibers, with large fibers more affected than small. There were a few ovoids of Wallerian degeneration. Cryostat sections showed significant loss of many large and fewer small myelinated fibers.

In summary, the muscle abnormalities were non-specific while the nerves showed severe loss of myelinated fibers and minor loss of small myelinated fibers. These findings were consistent with Friedreich's ataxia but the changes in small myelinated fibers were more marked than usual in this disorder. (Dr. Stirling Carpenter)

Patient 3 at age 7 had an EMG and nerve conduction study which was normal. Sensory evoked potentials were specifically studied to confirm the diagnosis of Friedreich's ataxia and were normal.

On repeat study at age 13 the $\mathrm{MCV}$ in the median nerve was normal at 50.1 $\mathrm{M} / \mathrm{sec}$. while the MCV in the posterior tibial nerve was marginally slow at $44.8 \mathrm{M} /$ sec. $(\mathrm{N}=48-56 \mathrm{M} / \mathrm{sec}$. $)$. No sensory evoked potentials could be obtained from the median nerve at the wrist. H-reflexes were absent in the leg. Three years later another study showed a marked change. The median nerve $\mathrm{MCV}$ had dropped to 45.3 $\mathrm{M} / \mathrm{sec}$. $(\mathrm{N}=50-58 \mathrm{M} / \mathrm{sec}$.), while the distal latency had risen to $4.5 \mathrm{M} / \mathrm{sec}$. $(\mathrm{N}=4.0 \mathrm{M} / \mathrm{sec}$.$) . The posterior tibial$ nerve failed to respond to maximal stimulation. Sensory potentials were again absent. EMG studies showed a profound reduction in m.u.p. recruitment with maximum effort. Motor unit configuration was normal. EMG results indicated an upper motor 
neuron lesion while the nerve conduction data suggested a concomitant disorder of lower motor neurons and primary sensory neurons.

\section{DISCUSSION}

a) Friedreich's Ataxia and Nephrotic Syndrome

A $4.2 \%$ prevalence of familial idiopathic nephrotic syndrome was reported by White (1973) in a survey of 24 European nephrology departments. Bader et al. (1974) in 70 patients with idiopathic nephrotic syndrome had 6 affected sibling pairs. Of our clinic's 187 children with MLNS, three had siblings with MLNS. These three families include the patients in the present report. The incidence of nephrotic syndrome has been estimated as $2 \times 10^{5}$ in New York (Schlesinger et al. 1968) and $6.9 \times 10^{5}$ in Indiana (Bader et al. 1974). Unfortunately, no figures are available for Quebec or Canada. The incidence of Friedreich's ataxia in Quebec has been estimated by Barbeau as $4 \times 10^{5}$.

Although there are problems in using figures from different countries to calculate the chance of the two conditions occurring together in a random sample, the probability is small. Depending on which estimates are used, the probability that Friedreich's ataxia and MLNS will occur together by chance ranges from $8 \mathrm{x}$ $10^{11}$ to $2.7 \times 10^{10}$. If one then takes into account the relative rarity of familial MLNS, the probability of Friedreich's ataxia and familial MLNS occurring together by chance becomes infinitely small.

The prevalence of nephrotic syndrome in Friedreich's ataxia was 3.5\% ( 2 of 58 patients) in comparison with $51.7 \%$ for cardiomyopathy and $19.0 \%$ for diabetes mellitus (Andermann et al. 1976).

Why these two conditions occurred together was unexplained and an underlying or common immunologic defect was not found. The association of hereditary spinocerebellar degeneration and immunologically mediated disease is however, not without precedent. Defects of humoral and cellular immunity occur in ataxia telangiectasia (McFarlin et al. 1972) and at least three patients with
Chediak-Higashi-Steinbrinck syndrome have developed a clinical picture resembling spinocerebellar degeneration (Sheremata et al. 1971).

\section{b) Friedreich's Ataxia and Epilepsy and Dyssynergia Cerebellaris Myoclonica}

The mother of the three children developed epilepsy at age 14. Her father's brother and one of her brother's children also had epilepsy (Figure 1). Our patient 1 had no seizure, but had a focal EEG abnormality; patient 2 had generalized seizures with onset at age 15, and multiple abnormal EEGs, but none of these showed spike wave discharges. Patient 3 had three convulsions as a child associated with fever, and at age 15 one or several generalized seizures. In addition she also had two bouts of myoclonic seizure activity at age 14 and 15 . Her EEG showed a spike wave abnormality.

Epileptic seizures are unusual in Friedreich's ataxia. Epileptic generalized seizures and myoclonic seizures have been reported in patients with Ramsay Hunt's Dyssynergia Cerebellaris Myoclonica (DCM). Ziegler et al. (1974) postulated involvement of cerebellar Purkinje cells and the dentate nucleus, a feature of only some cases of Friedreich's ataxia. At autopsy such lesions were seen in our patient 2.

An alternative explanation for the seizures in our patients may be that they have inherited the EEG trait from their mother (Metrakos and Metrakos 1961), and in the presence of the neurological deficits of Friedreich's ataxia this is expressed as a seizure disorder in two, and an EEG abnormality in the third. This may be a factor in other patients considered to have DCM. Ziegler's patient had a spike wave abnormality but there was no family history of EEG abnormality or seizures.

\section{c) Friedreich's Ataxia and \\ Peripheral Nervous System}

Friedreich's ataxia is a disease with pathological changes mainly localized to the posterior columns and spinocerebellar and corticospinal tracts of the spinal cord. Involvement of the peripheral nerves may occur, but clinical assessment of such involvement is often prejudiced by the coexistent lesions which are situated at more proximal levels in the nervous system. Sensory nerve action potentials may disclose evidence of peripheral nerve involvement and together with evidence of cardiac involvement help to differentiate Friedreich's ataxia from similar diseases.

Patient 1 and patient 2 had similar electrophysiological findings at comparable ages. Motor conduction velocities (MCV) values are slightly diminished in Friedreich's ataxia (Salisachs et al 1975). This is likely due to a slow "dying back" type of axonal degeneration due to disease of the anterior horn cells affecting predominantly the largest diameter fiber population. Our patients had slightly decreased MCVs (44M/sec.) with normal terminal motor latencies and evoked potentials of normal shape and amplitude.

In Friedreich's ataxia sensory action potentials are reduced in amplitude or absent (Hughes, Brownell et al. 1972) consistent with the pathology which shows a fall-out of large diameter sensory fibers in peripheral nerves. Sensory evoked potentials could not be obtained in either of our patients. The combined findings of reduced amplitude and/or absence of sensory action potentials, combined with relative sparing of motor conduction velocity is characteristic of Friedreich's ataxia patients and was seen in our patients. The sural nerve biopsy done in patient 2 showed mostly loss of large myelinated fibers while smaller fibers were affected to a lesser degree.

In patients 2 and 3 motor conduction velocities were normal at age 6 and 7 respectively and in patient 3 sensory potentials were shown to be present also. By age 14 or 15 motor conduction velocities were slowed and sensory potentials were absent in both patients. From these limited data there was no evidence the corticosteroids and other immunosuppressive medications used at age 6 years, in patient 2 , had any beneficial effect on the progress of these changes.

Since sensory potentials were present at age 7 in patient 3 and absent by 
adolescence in both patients 2 and 3 it seems the presence of sensory potentials at age 7 or 8 years does not exclude the diagnosis of Freidreich's ataxia while their presence in adolescence would be strongly against it.

d) Friedreich's Ataxia and the Heart

The heart in patients with Friedreich's ataxia shows hypertrophy of muscle fibers and extensive interstitial fibrosis with focal muscle fiber degeneration (Blackwood and Corsellis, 1976). The post-mortem study of patient 2 showed diffuse interstitial fibrosis throughout the myocardium with focal myofibrillar degeneration affecting myocardial fibers of varying size although most were large, typical of Friedreich's ataxia.

Hewer (1969), in 20 of 24 patients with Friedreich's ataxia noted extensive $T$-wave inversion in the left ventricular epicardial leads, as was found in all three of our patients. An echocardiogram of patient 3 showed the typical features seen in Friedreich's ataxia.

\section{ACKNOWLEDGEMENT}

We wish to thank Dr. André Barbeau of the Clinical Research Institute of Montreal for providing the estimate on the incidence of Friedreich's ataxia in Quebec.

\section{REFERENCES}

ANDERMANN, E., REMILLARD, G.M. GOYER, C., BLITZER, L., ANDERMANN, F., and BARBEAU, A. (1976). Genetic and family studies in Friedreich's Ataxia. Canad. J. Neurol. Sci. 3: 287-301.

BADER, P.I., GROVES, J., TRYGSTAD, C.W., and NANCY, W.E. (1974). Familial nephrotic syndrome. Am. J. Med. 56: 34-43.

BLACKWOOD, W., CORSELLIS, J.A.N. Greenfield's Neuropathology. 3rd Edition, 1976.

HEWER, R.L. (1969). The heart in Friedreich's Ataxia. British Heart Journal 31: 5-14, 1969.

HUGHES, J.T., BROWNELL, B., and HEWER, R.L. (1972). The peripheral sensory pathway in Friedreich's Ataxia. Brain 91: 803-818.

McFARLIN, D.E., STROBER, W., WALDMAN, I.A. (1972). Ataxia telangiectasia. Medicine (Baltimore) 51: 281-314.

METRAKOS, K., and METRAKOS, J.D. (1961). Genetics of Convulsive Disorders. II Genetic and Electroencephalographic Studies in Centrencephalic Epilepsy. Neurol. II: 474-483.

SALISACHS, M., CODINA, M., and PRADAS, J. (1975). Motor conduction velocity with Friedreich's Ataxia. J. Neurol. Sci., 24: 331-337.

SCHLESINGER, E.R., SULTZ, H.A., MOSHER, W.E., and FELDMAN, J.G. (1968). The nephrotic syndrome - its incidence and implications for the community. Am. J. Dis. Child. 116: 623.

SHEREMATA, W., KOTT, S., and CYR, D.F. (1971). The Chediak-Higashi-Steinbrinck syndrome. Arch. Neurol. 25: 289-294.

WHITE, R.M.R. (1973). The familial nephrotic syndrome: I.A. European survey. Clinical Nephrology 1: 215-219.

ZIEGLER, D.K., VAN SPEYBROECH, N.W., and SEITZ, E.F. (1974). Myoclonic epilepsia partialis continua and Friedreich's ataxia. Arch. Neurol. 31: 308-311. 